\title{
Neutrophilic Alveolitis and High Serum Pro-Brain Natriuretic Peptide Level may be Indicators of Pulmonary Functional Impairment in Connective Tissue Disorders
}

\author{
Serap UNCULU, ${ }^{1}$ Özlem Erçen DİKEN, ${ }^{1}$ Aydın ÇİLEDAĞ, ${ }^{1}$ Aydan İKİNCİOĞULLARI, ${ }^{2}$ \\ Demet KARNAK, ${ }^{1}$ Oya KAYACAN,${ }^{1}$ Murat TURGAY ${ }^{3}$ \\ ${ }^{1}$ Department of Chest Diseases, Medical Faculty of Ankara University, Ankara, Turkey \\ ${ }^{2}$ Department of Pediatric Allergy and Immunology, Medical Faculty of Ankara University, Ankara, Turkey \\ ${ }^{3}$ Department of Rheumatology, Medical Faculty of Ankara University, Ankara, Turkey
}

\begin{abstract}
Objectives: This study aims to assess the role of several diagnostic tests and tools, immune markers, and the association between serum pro-brain natriuretic peptide levels and other parameters in patients with collagen tissue disorders with pulmonary involvement.

Patients and methods: In this prospective study, 62 patients ( 17 males, 45 females; mean age $58.1 \pm 13.6$ years; range 24 to 87 years) with pulmonary involvement of connective tissue disorders were evaluated using several functional parameters (six-minute walking test, serum pro-brain natriuretic peptide, echocardiographic measurement of the pulmonary pressure, respiratory functional parameters, and blood pressure measurement), bronchoalveolar lavage differential cytology and/or flow cytometric analysis.

Results: Duration of disease was 7.6 years. Diagnoses included rheumatoid arthritis (38.7\%), scleroderma (38.7\%), primary Sjögren's syndrome $(16.1 \%)$, mixed collagen tissue disorder $(4.8 \%)$, and systemic lupus erythematosus (1.6\%). Pulmonary hypertension was present in $38.7 \%$ of the patients with the highest incidence of rheumatoid arthritis showing reduced respiratory functions, partial oxygen pressure, and six-minute walk distance, as well as increased serum pro-brain natriuretic peptide and neutrophilic alveolitis.

Conclusion: High serum pro-brain natriuretic peptide levels and neutrophilic alveolitis may provide diagnostic clues for a possible diagnosis of pulmonary hypertension and impaired respiratory functions.

Keywords: Bronchoalveolar lavage; collagen tissue disorder; pro-brain natriuretic peptide; pulmonary arterial hypertension; six-minute walking test.
\end{abstract}

Collagen tissue disorders (CTD) encompass a variety of diseases including rheumatoid arthritis (RA), systemic lupus erythematosus (SLE), progressive systemic sclerosis (PSS), Sjögren's syndrome (SS), polymyositis-dermatomyositis, and mixed collagen tissue disorders (MCTD). Any tissue of the respiratory system namely bronchi, interstitium and pleura, may be involved in patients with CTD. ${ }^{1,2}$

Despite the reported differences in the incidence of interstitial pulmonary disease among different CTDs, the estimated overall incidence is approximately $15 \%$. In RA, the reported frequency of pulmonary involvement ranges between 19 and $67 \%$, while the corresponding figure in patients with MCTD or PSS is $85 \%$. The reported figures for SLE and polymyositis-dermatomyositis vary between 23 and 38\%, respectively. ${ }^{3-5}$

Early diagnosis of pulmonary involvement of CTD has important implications with regard to the choice of therapy. Manifest respiratory symptoms usually imply irreversible changes in the lung

Received: July 14, 2015 Accepted: July 28, 2015 Published online: August 23, 2015

Correspondence: Demet Karnak, MD. Ankara Üniversitesi Tıp Fakültesi Göğüs Hastalıkları Anabilim Dalı, 06100 Cebeci, Ankara, Turkey.

Tel: +90 506 - 5818224 e-mail: demet.karnak@gmail.com

(2016 Turkish League Against Rheumatism. All rights reserved. 
parenchyma. Therefore, several strategies such as clinical evaluation, respiratory function tests, exercise tests, imaging studies, bronchoalveolar lavage (BAL), and certain serum markers are commonly utilized for the follow-up assessment of patients with CTD. ${ }^{3-5}$

Pulmonary involvement of CTD may result in the detection of alveolitis characterized by the accumulation of active alveolar macrophages, neutrophils, lymphocytes, and eosinophils in BAL. Predominantly neutrophilic alveolitis detected by BAL has a more progressive course, with a more extensive involvement in computed tomography images. These findings may influence the therapeutic decisions and help in prognostic predictions.

Pulmonary hypertension $(\mathrm{PH})$ is a serious and progressive complication of the pulmonary involvement of CTD. PH may also occur without the presence of significant parenchymal lung disease. PSS represents the collagen tissue disorder with the highest prevalence of $\mathrm{PH}$ (i.e. between 9 and 13\%), ${ }^{6}$ leading to deaths mostly resulting from cardiopulmonary involvement. Therefore, early diagnosis and treatment of $\mathrm{PH}$ bear important clinical significance.

Serum pro-brain natriuretic peptide (pro-BNP) is used as a diagnostic and prognostic marker in cardiovascular diseases. In patients with PSS, studies have shown that serum pro-BNP levels may be used as an early indicator of $\mathrm{PH}{ }^{7}$

Thus, in this study we aimed to assess the role of several diagnostic tests and tools, immune markers, and the association between serum pro-BNP levels and other parameters in patients with CTD with pulmonary involvement.

\section{PATIENTS AND METHODS}

A total of 62 patients (17 males, 45 females; mean age $58.1 \pm 13.6$ years; range 24 to 87 years) attending to the Department of Chest Diseases with the referral of Department of Rheumatology of Medical Faculty of Ankara University between December 2008 and September 2009 with a diagnosis of PSS, RA, SS, MCTD, or SLE and radiological pulmonary involvement were prospectively evaluated. All patients provided written informed consent according to Helsinki declaration and local ethical committee approval was also gained (29 $9^{\text {th }}$ Jun 2009, 154-4972). CTD was diagnosed according to American College of Rheumatology criteria. $^{8-11}$

Dyspnea was graded according to New York Heart Association (NYHA) and World Health organization (WHO) classification schemes. Posteroanterior chest X-ray, electrocardiography, and high resolution computed tomography (HRCT) were performed in all patients. Pulmonary function tests (PFT) including dynamic lung volume, diffusing capacity of lung for carbon monoxide (DLCO) and DLCO divided by alveolar volume were performed. Dynamic lung volumes and flow rates were extrapolated from the forced expiratory slope. Forced vital capacity (FVC), forced expiratory volume in 1 second $\left(F E V_{1}\right)$, $\mathrm{FEV}_{1} / \mathrm{FVC}$, forced expiratory flow (FEF25-75), FEF25, FEF50, FEF75 and peak expiratory flow were measured using forced expiratory values. The values were expressed as percentage of the expected for each patient. Tests complying with the criteria of the American Thorax Society were qualified for the study procedures. For the expected values, the reference values issued by the European Cooperation for Space Standardization were used (European Respiratory Society update 1993). ${ }^{12}$ Large airway obstruction can be detected as reduced $\mathrm{FEV}_{1} / \mathrm{FVC}$ of $70 \%{ }^{13}$ FEF25-75 in other words forced expiratory flow at 25-75 percent of FVC is the spirometric variable most commonly cited as an indicator of small airways obstruction especially below $60 \% .{ }^{14}$

Arterial blood gases were analyzed while resting and breathing ambient room air. Arterial partial oxygen pressure $\left(\mathrm{PaO}_{2}\right), \mathrm{pH}$, partial carbon dioxide pressure, and oxygen saturation $\left(\mathrm{SaO}_{2}\right)$ were measured and recorded. Mild, moderate and severe hypoxemia were assessed according to $\mathrm{PaO}_{2}$ level as $<80,<60$ and $<40 \mathrm{mmHg}$, respectively. ${ }^{15}$

Functional exercise capacity was determined based on the result of six-minute walk test (6MWT). Until now, no standard threshold levels have been reported for 6MWT distance. In previous studies involving patients with $\mathrm{PH}$, higher mortality was reported for a walking distance below 380 meters, resulting in the common utilization of this value as a threshold. ${ }^{16}$ 
Thus, we also adopted this threshold value of 380 meters as well as a four-point reduction in $\mathrm{SaO}_{2}$ for our study procedures.

Presence of $\mathrm{PH}$ was ascertained via non-invasive diagnostic modality, i.e. echocardiography. A systolic pulmonary arterial pressure (sPAP) over $35 \mathrm{mmHg}$ was considered diagnostic for PH. ${ }^{17}$

Flexible bronchoscopy and BAL were performed in all patients who had no contraindications and consented for the procedure. A neutrophil percentage of $>4 \%$ was used to make a diagnosis of neutrophilic alveolitis, and a lymphocyte percentage $>14 \%$ was taken as an indication for the presence of lymphocytic alveolitis. Immunophenotypic analysis of BAL samples were carried out by three color staining using CD45, CD3, CD4, CD8 monoclonal antibodies (BeckmanCoulter, Marseille, France) and flow cytometer (FC500 Cytomics, Beckman Coulter, Miami, USA) equipped with an argon-ion laser. CD4+/CD8+ ratio was considered low if it was $<1.6$ and high if it was $>1.6$.

Also, serum pro-BNP, hemoglobin, erythrocyte sedimentation rate, $\mathrm{C}$-reactive protein, and auto-immune markers were assayed.

\section{Statistical analysis}

Statistical analyses were performed using SPSS for Windows version 14.0 software (SPSS Inc., Chicago, IL, USA) at the Department of Biostatistics, Medical Faculty of Ankara University. The association between tested parameters was examined using Spearman's correlation test. Patients were sub-categorized based on the following parameters: a sPAP $<35 \mathrm{mmHg}$ or $>35 \mathrm{mmHg}$, 6MWT distance $<380 \mathrm{~m}$ or $>380 \mathrm{~m}$, presence or absence of honeycombing and ground-glass appearance in thorax HRCT, characteristics of BAL results, and positivity or negativity of immune markers. The pairwise comparisons for the resultant subgroups were performed using "MannWhitney U" and "Student t" tests. $\mathrm{SaO}_{2}$ changes in 6MWT were assessed using Chisquare test.

\section{RESULTS}

Number of patients with RA, PSS, SS, MCTD and SLE were 24 (38.7\%), 24 (38.7\%), 10 (16.1\%), three (4.8\%), and one (1.6\%), respectively. Table 1 summarizes the general patient characteristics and functional parameters.

Table 1. General characteristics and functional parameters of patients

\begin{tabular}{|c|c|c|c|c|}
\hline & $\mathrm{n}$ & Mean \pm SD & Min.-Max. & Median \\
\hline Age (year) & 62 & $58.1 \pm 13.6$ & $24-87$ & 59.5 \\
\hline Duration of disease (year) & 62 & $7.5 \pm 5.7$ & $1-25$ & 6 \\
\hline Duration of pulmonary involvement (year) & 62 & $3.5 \pm 3.43$ & $1-20$ & 2.5 \\
\hline Systolic pulmonary arterial pressure $(\mathrm{mmHg})$ & 60 & $34.5 \pm 17.8$ & $20-100$ & 30 \\
\hline Forced vital capacity (\%) & 60 & $86.7 \pm 24.9$ & $40-140$ & 88.5 \\
\hline Forced expiratory volume in one second (\%) & 60 & $84.8 \pm 23.1$ & $30-130$ & 85.5 \\
\hline Forced expiratory volume in one second/Forced vital capacity & 60 & $81.9 \pm 9.4$ & $40-100$ & 82 \\
\hline Forced expiratory volume at $25-75$ percent of forced vital capacity & 60 & $75.6 \pm 26.0$ & $9-125$ & 75 \\
\hline Diffusing capacity of lung for carbon monoxide (\%) & 58 & $64.6 \pm 24.3$ & $18-122$ & 62 \\
\hline $\begin{array}{l}\text { Diffusing capacity of lung for carbon monoxide divided by alveolar } \\
\text { volume (\%) }\end{array}$ & 58 & $76.6 \pm 20.4$ & $40-117$ & 75 \\
\hline Partial oxygen pressure $(\mathrm{mmHg})$ & 62 & $69.9 \pm 13.5$ & $30-94$ & 72 \\
\hline Partial carbon dioxide pressure $(\mathrm{mmHg})$ & 62 & $34.5 \pm 4.1$ & $23-45$ & 35 \\
\hline Arterial oxygen saturation (\%) & 62 & $92.2 \pm 6.9$ & $59-98$ & 94 \\
\hline Six-minute walk test $(\mathrm{m})$ & 58 & $398 \pm 122$ & $52-615$ & 432 \\
\hline Desaturation (\%) & 58 & $2.2 \pm 3.9$ & $0-17$ & 0 \\
\hline Borg scale (before 6-minute walk test) & 58 & $0.9 \pm 1.3$ & $0-6$ & 1 \\
\hline Borg scale (after 6-minute walk test) & 58 & $2.9 \pm 2.2$ & $0-9$ & 3 \\
\hline Pro-brain natriuretic peptide (pg/mL) & 55 & $101.6 \pm 142.7$ & $6-950$ & 54 \\
\hline Erythrocyte sedimentation rate $(\mathrm{mm} / \mathrm{h})$ & 62 & $39.3 \pm 23.6$ & $6-94$ & 30 \\
\hline C-reactive protein $(\mathrm{mg} / \mathrm{L})$ & 61 & $7.9 \pm 13.4$ & $0.02-73$ & 3.1 \\
\hline Hemoglobin (g/dL) & 62 & $12.6 \pm 1.7$ & 9.3-17.9 & 12.4 \\
\hline Rheumatoid factor (IU/L) & 61 & $134 \pm 314.3$ & $6.9-1980$ & 12.2 \\
\hline
\end{tabular}


Duration of disease was $7.5 \pm 5.7$ years whereas pulmonary involvement duration was $3.5 \pm 3.4$ years. As of the study entry, 16 patients (25.8\%) were current smokers, and dyspnea was the most common symptom reported by 57 patients (91.9\%). Majority of the participants' WHO functional classes were I $(\mathrm{n}=22 ; 35.4 \%)$ and II ( $\mathrm{n}=24 ; 38.7 \%)$. According to Medical Research Council (MRC) classification, majority of the study subjects' MRC classes were I $(\mathrm{n}=25 ; 40.3 \%)$ and II $(\mathrm{n}=22 ; 35.4 \%)$.

Rheumatoid factor positivity was detected in $21 / 24,3 / 24,4 / 10,1 / 3$ and $1 / 1$ of the patients with RA, PSS, SS, MCTD, and SLE, respectively. The corresponding figures for antinuclear antibody positivity were $5 / 24$, $23 / 24,8 / 10,1 / 3$, and $1 / 1$, respectively. Antidouble stranded deoxyribonucleic acid was positive in one of the 24 patients with PSS. Anti-neutrophil cytoplasmic antibodies were positive in $1 / 14 \mathrm{RA}$ and $1 / 10$ SS patients. Topoisomerase 1 positivity was observed in 13/24 PSS patients. Sjögren's syndrome antigen A was positive in 2/24 RA, 4/24 PSS, and 7/10 SS patients. Sjögren's syndrome antigen $B$ positivity was present in $5 / 10$ SS patients. Centromeric protein-B was positive in $3 / 24$ PSS and $1 / 10$ SS patients. Histidyl-transfer ribonucleic acid synthetase was positive in $1 / 24 \mathrm{RA}$ and $1 / 24$ PSS patients. Anti-U1ribonucleoprotein was positive in $2 / 24$ PSS and $1 / 1$ SLE patients. Anti-cyclic citrullinated peptide positivity was found in 5/24 RA patients.

As opposed to 16 patients (25.8\%) who were current smokers, 46 patients (74.2\%) were not smoking. The two groups were not significantly different in terms of the results of PFTs, blood gas analysis, pro-BNP and BAL parameters $(p>0.05)$. However, a significantly lower 6MWT distance was observed in smokers in comparison with non-smokers $(386.2 \pm 114.8$ vs. $431.2 \pm 139.5 ; p<0.05)$. Fifty-four patients had normal or increased $\mathrm{FEV}_{1} / \mathrm{FVC}$. Large airway obstruction $\left(\mathrm{FEV}_{1} / \mathrm{FVC}<70 \%\right)$ was found in six cases, of whom three were cigarette smoking RA patients. The remaining three non-smokers were diagnosed with PSS, MCTD or SS. A total of 19 patients (30.6\%) had small airway obstruction (FEF25-75 $\leq 60 \%$ ), with only three having a smoking history. Majority of the subjects with small airway obstruction $(50 \%, n=10)$ had RA.

Mean DLCO was $64.6 \pm 24.3 \%$ in CTD patients. Nineteen patients (30.6\%) were normoxemic, as compared to mild hypoxemia in 30 (48.3\%) or moderate hypoxemia in $11(17.7 \%)$ patients. Only two patients (3.2\%) had severe hypoxemia.

An echocardiographic examination was performed in 60 patients. Thirty-six patients (60\%) had a sPAP below $35 \mathrm{mmHg}$, while 13 (21.6\%) had a sPAP between 36 and $45 \mathrm{mmHg}$,

Table 2. Comparison between patients who had systolic pulmonary arterial pressure of $<35 \mathrm{mmHg}$ or systolic pulmonary arterial pressure of $>35 \mathrm{mmHg}$

\begin{tabular}{|c|c|c|}
\hline \multirow[t]{2}{*}{ Parameters } & \multirow{2}{*}{$\frac{\mathrm{sPAP}>35 \mathrm{mmHg} \quad(\mathrm{n}=24)}{\text { Mean } \pm \mathrm{SD}}$} & \multirow{2}{*}{$\frac{\mathrm{sPAP}<35 \mathrm{mmHg} \quad(\mathrm{n}=36)}{\text { Mean } \pm \text { SD }}$} \\
\hline & & \\
\hline Age (year) & $59.95 \pm 12.7$ & $57.0 \pm 14.3$ \\
\hline Duration of disease (year) & $8.1 \pm 5.7$ & $7.1 \pm 5.8$ \\
\hline Duration of pulmonary involvement (year) & $3.4 \pm 2.9$ & $3.7 \pm 3.7$ \\
\hline New York Heart Association & $2.4 \pm 0.9$ & $1.6 \pm 0.7^{* * * *}$ \\
\hline Forced vital capacity (\%) & $77.8 \pm 92.3$ & $92.3 \pm 21.1^{*}$ \\
\hline Forced expiratory volume in one second (\%) & $75.0 \pm 23.2$ & $90.9 \pm 21.2^{* *}$ \\
\hline Forced expiratory volume in one second/Forced vital capacity & $83.4 \pm 9.6$ & $80.9 \pm 9.2$ \\
\hline Forced expiratory flow at 25-75 percent of forced vital capacity (\%) & $67.9 \pm 24.4$ & $80.5 \pm 26.2^{*}$ \\
\hline Diffusing capacity of lung for carbon monoxide (\%) & $53.5 \pm 24.2$ & $71.4 \pm 21.9^{* * *}$ \\
\hline Six-minute walk test $(\mathrm{m})$ & $333.9 \pm 139.4$ & $444.8 \pm 83.9^{* *}$ \\
\hline Desaturation $\left(\Delta \mathrm{SO}_{2}\right)$ & $3.9 \pm 4.9$ & $1.0 \pm 2.5^{* * *}$ \\
\hline Partial oxygen pressure $(\mathrm{mmHg})$ & $61.3 \pm 14.0$ & $75.5 \pm 9.9^{* * *}$ \\
\hline Partial carbon dioxide pressure $(\mathrm{mmHg})$ & $34.0 \pm 5.0$ & $34.8 \pm 3.5$ \\
\hline Arterial oxygen saturation (\%) & $88.4 \pm 9.6$ & $94.5 \pm 2.4^{* * *}$ \\
\hline Pro-brain natriuretic peptide $(\mathrm{pg} / \mathrm{mL})$ & $191.4 \pm 190.8$ & $41.8 \pm 35.7^{* * *}$ \\
\hline Bronchoalveolar lavage lymphocyte (\%) & $13.6 \pm 15.1$ & $15.2 \pm 11.9$ \\
\hline Bronchoalveolar lavage neutrophil (\%) & $16.7 \pm 12.7$ & $6.0 \pm 8.6^{* * * *}$ \\
\hline
\end{tabular}


seven (11.6\%) between 46 and $55 \mathrm{mmHg}$, and four $(6.6 \%)$ greater than $56 \mathrm{mmHg}$. Pulmonary arterial hypertension was present in $11 / 24$ (45.8\%), 9/24 (37.5\%), 3/10 (30\%), 0/3 (0\%), and $1 / 1(100 \%)$ of patients with RA, PSS, SS, MCTD, and SLE, respectively. Subjects with PH had significantly higher NYHA score, impaired PFT parameters including FVC, FEV 1 , FEF25-75, and DLCO. 6MWT distance and $\mathrm{PO}_{2}$ of patients were significantly lower and they desaturated significantly in 6MWT. Their pro-BNP and BAL neutrophil percentages were also higher (Table 2). The patients with a 6MWT distance $<380$ meters were significantly older and had higher NYHA score, lower oxygen values $\left(\mathrm{PaO}_{2}\right.$ and $\left.\mathrm{SaO}_{2}\right)$, higher sPAP, pro-BNP and BAL neutrophil count. Also, a comparison was made between these parameters in patients who had a 6MWT distance of less or more than 380 meters. Patients with lower than 380 meters of 6MWT distance had significantly higher oxygen desaturation amount (1.37 \pm 3.4 vs. $4.2 \pm 4.4$; $\mathrm{p}<0.01$ ) (Table 3).

All patients underwent a thorax HRCT. In 12 patients with a normal chest X-ray, pulmonary involvement was suspected. Most frequent HRCT findings were ground-glass appearance $(n=45,74.2 \%)$ and interseptal thickening $(n=36,58.1 \%)$. Honeycombing was present in 24 patients (38.7\%). Patients with or without honeycombing in computed tomography imaging were also compared in terms of study parameters. Patients with honeycombing had significantly lower FVC\% $(77.8 \pm 21.2$ vs. $92.8 \pm 25.7 ; \mathrm{p}<0.05)$ and DLCO $\%(50.2 \pm 15.6$ vs. $74.8 \pm 24.3 ; \mathrm{p}<0.001)$.

Mean pro-BNP was $101.6 \pm 142.8 \mathrm{pg} / \mathrm{mL}$ in our study (normal range below $125 \mathrm{pg} / \mathrm{mL}$ ). However, it was significantly higher in patients with $\mathrm{PH}$ than patients without $\mathrm{PH}(91.4 \pm 190.8$ vs. $41.8 \pm 35.7$; $\mathrm{p}<0.001$ ) (Table 2). Unlike neutrophilic alveolitis, patients with lymphocytic alveolitis had lower sPAP values and showed less desaturation in 6MWT.

While BAL showed no signs of alveolitis in eight patients; 20, 19 and three patients had neutrophilic, lymphocytic and mixed type alveolitis, respectively. The differences in BAL findings between different subgroups of CTD were evaluated. Patients with RA or SS had mostly lymphocytic alveoilitis $(42.1 \%$ and $62.5 \%$, respectively) as compared to more frequent occurrence of neutrophilic alveolitis in PSS patients (47.6\%). CD4+/CD8+ ratio was also compared. Most patients with RA, PSS or SS had decreased CD4+/CD8+ ratio (57.9\%, $66.6 \%$ and $75 \%$, respectively). However, proportion of patients with an increased

Table 3. Comparison between patients who had a six-minute walk test of less or more than $380 \mathrm{~m}$

\begin{tabular}{|c|c|c|}
\hline \multirow[t]{2}{*}{ Parameters } & $>380 \mathrm{~m}$ & $<380 \mathrm{~m}$ \\
\hline & Mean \pm SD & Mean \pm SD \\
\hline Age (year) & $53.10 \pm 10.9$ & $67.3 \pm 13.4^{* * * *}$ \\
\hline Duration of disease (year) & $6.8 \pm 5.5$ & $8.8 \pm 6.2$ \\
\hline Duration of pulmonary involvement (year) & $3.3 \pm 2.6$ & $4.0 \pm 4.6$ \\
\hline New York Heart Association & $1.5 \pm 0.6$ & $2.7 \pm 0.9^{* * * *}$ \\
\hline Forced vital capacity (\%) & $90.7 \pm 21.6$ & $79.3 \pm 29.1$ \\
\hline Forced expiratory volume in one second (\%) & $87.6 \pm 20.9$ & $79.5 \pm 26.4$ \\
\hline Forced expiratory volume in one second/Forced vital capacity & $79.6 \pm 9.0$ & $86.0 \pm 8.8^{*}$ \\
\hline Forced expiratory flow at 25-75 percent of forced vital capacity (\%) & $74.6 \pm 26.3$ & $77.5 \pm 26.1$ \\
\hline Diffusing capacity of lung for carbon monoxide (\%) & $68.6 \pm 24.3$ & $56.5 \pm 22.8$ \\
\hline Desaturation $\left(\Delta \mathrm{SO}_{2}\right)$ & $1.4 \pm 3.4$ & $4.2 \pm 4.4^{* *}$ \\
\hline Borg scale (before 6-minute walk test) & $0.3 \pm 0.5$ & $2.3 \pm 1.7^{* * * *}$ \\
\hline Borg scale (after 6-minute walk test) & $1.8 \pm 1.4$ & $5.3 \pm 1.8^{* * * *}$ \\
\hline Partial oxygen pressure $(\mathrm{mmHg})$ & $74.1 \pm 11.9$ & $62.4 \pm 13.3^{* * * *}$ \\
\hline Partial carbon dioxide pressure $(\mathrm{mmHg})$ & $34.5 \pm 4.00$ & $34.5 \pm 4.5$ \\
\hline Arterial oxygen saturation (\%) & $93.5 \pm 6.1$ & $89.8 \pm 7.7^{* * *}$ \\
\hline Systolic pulmonary arterial pressure $(\mathrm{mmHg})$ & $29.2 \pm 8.3$ & $45.2 \pm 25.8^{*}$ \\
\hline Pro-brain natriuretic peptide $(\mathrm{pg} / \mathrm{mL})$ & $68.4 \pm 64.3$ & $164.5 \pm 216.2^{*}$ \\
\hline Bronchoalveolar lavage neutrophil (\%) & $5.9 \pm 7.4$ & $18.2 \pm 13.8^{* * *}$ \\
\hline Bronchoalveolar lavage lymphocyte (\%) & $18.4 \pm 14.2$ & $7.4 \pm 6.1^{* * *}$ \\
\hline
\end{tabular}


Table 4. Comparison between patients with neutrophilic or lymphocytic alveolitis

\begin{tabular}{|c|c|c|}
\hline \multirow[t]{2}{*}{ Parameters } & Neutrophilic & Lymphocytic \\
\hline & Mean \pm SD & Mean \pm SD \\
\hline Age (year) & $66.4 \pm 11.6$ & $56.7 \pm 10.5^{* *}$ \\
\hline Duration of disease (year) & $7.6 \pm 5.2$ & $6.0 \pm 4.1$ \\
\hline Duration of pulmonary involvement (year) & $3.8 \pm 2.7$ & $3.0 \pm 2.8$ \\
\hline New York Heart Association & $2.5 \pm 0.9$ & $1.4 \pm 0.5^{* * * *}$ \\
\hline Forced vital capacity (\%) & $73.4 \pm 28.0$ & $99.7 \pm 21.2^{* *}$ \\
\hline Forced expiratory volume in one second (\%) & $73.4 \pm 25.7$ & 96. $9 \pm 19.9^{* * *}$ \\
\hline Forced expiratory volume in one second/Forced vital capacity & $86.3 \pm 9.4$ & $80.4 \pm 6.9^{*}$ \\
\hline Forced expiratory flow at 25-75 percent of forced vital capacity (\%) & $83.8 \pm 29.4$ & $78.1 \pm 25.4$ \\
\hline Diffusing capacity of lung for carbon monoxide (\%) & $48.7 \pm 16.9$ & $73.1 \pm 25.6^{* * *}$ \\
\hline Systolic pulmonary arterial pressure $(\mathrm{mmHg})$ & $43.9 \pm 24.9$ & $29.5 \pm 9.4^{*}$ \\
\hline Partial oxygen pressure (mmHg) & $62.5 \pm 13.2$ & $74.6 \pm 11.2^{* *}$ \\
\hline Partial carbon dioxide pressure $(\mathrm{mmHg})$ & $34.9 \pm 5.0$ & $33.2 \pm 3.9$ \\
\hline Arterial oxygen saturation (\%) & $88.6 \pm 8.9$ & $94.3 \pm 3.0^{* * *}$ \\
\hline Six-minute walk test $(\mathrm{m})$ & $312.5 \pm 132.4$ & $449.2 \pm 61.1^{* * *}$ \\
\hline Desaturation (\%) & $3.9 \pm 4.3$ & $1.8 \pm 4.2$ \\
\hline Pro-brain natriuretic peptide $(\mathrm{pg} / \mathrm{mL})$ & $115.6 \pm 102.5$ & $70.0 \pm 67.1$ \\
\hline
\end{tabular}

CD4+/CD8+ ratio was higher among patients with RA (42.1\%) as compared to those among patients with PSS and SS (33.3\% and 25\%, respectively). A comparison of patients with neutrophilic vs. lymphocytic alveolitis revealed that patients with neutrophilic alveolitis had significantly higher NYHA score and restrictive pulmonary function pattern with lower FVC, $\mathrm{FEV}_{1}, \mathrm{FEV}_{1} / \mathrm{FVC}$ and DLCO. They also had a higher sPAP, lower $\mathrm{PaO}_{2}$ and $\mathrm{SaO}_{2}$ along with a shorter 6MWD (Table 4).

Consistent with these findings, BAL neutrophilia negatively correlated with these parameters (FVC, FEV $2, \mathrm{DLCO}, \mathrm{PaO}_{2}$ and $\mathrm{SaO}_{2}$ ) whereas it positively correlated with sPAP, pro-BNP and desaturation in 6MWT (Table 5).

\section{DISCUSSION}

Pulmonary involvement represents an important complication in CTDs, with varying degrees of involvement reported for different disease categories. ${ }^{18}$ Consistent with the literature data, patients with rheumatoid arthritis and progressive systemic sclerosis comprised the majority of our study subjects.

Pulmonary involvement developed in CTD patients within approximately four years after diagnosis. Compatible with previous reports, the most common symptom observed in our study was dyspnea which, in a patient with CTD, requires clinical, radiological, and functional assessments for determining the presence of possible pulmonary involvement.

Table 5. Correlation between bronchoalveolar lavage neutrophil percentage and other parameters

\begin{tabular}{lcc}
\hline & Coefficient of correlation (r) \\
\hline Forced vital capacity (\%) & -0.399 & $p$ \\
Forced expiratory volume in one second (\%) & -0.408 & $0.005^{*}$ \\
Forced expiratory volume in one second/Forced vital capacity & 0.397 & $0.004^{*}$ \\
Forced expiratory flow at 25-75 percent of forced vital capacity (\%) & 0.101 & $0.005^{*}$ \\
Diffusing capacity of lung for carbon monoxide (\%) & -0.550 & 0.494 \\
Partial oxygen pressure (mmHg) & 0.531 & $0.000^{*}$ \\
Arterial oxygen saturation (\%) & -0.475 & $-0.000^{*}$ \\
Systolic pulmonary arterial pressure (mmHg) & 0.546 & $0.000^{*}$ \\
Pro-brain natriuretic peptide (pg/mL) & 0.338 & $0.000^{*}$ \\
Six-minute walk test (m) & -0.550 & $0.020^{*}$ \\
Desaturation (\%) & 0.413 & $0.000^{*}$ \\
"Significant positive correlation between bronchoalveolar lavage neutrophil percentage and forced expiratory volume in one second/Forced vital capacity, systolic \\
pulmonary arterial pressure, pro-brain natriuretic peptide and desaturation.
\end{tabular}


Approximately one-fourth of our study population was smokers. Kim et al. ${ }^{5}$ showed that cigarette smoking was a risk factor for RA associated interstitial lung disease. In line with previous reports, approximately half of our patients with RA -a higher proportion of patients compared to other patient groups- had smoking history. This clearly demonstrates the importance of cigarette cessation for the prevention of pulmonary complications particularly in patients with RA.

Small airway disease mostly occurs in RA patients with pulmonary involvement as compared to other CTDs. ${ }^{5}$ While some authors propose that pulmonary involvement affects the small airways initially, others hold the view that this finding is mostly associated with cigarette smoking independent of the underlying condition. ${ }^{19}$ Approximately one third of our patients had small airway disease manifesting itself with reduced FEF25-75\%. In line with the literature reports, RA patients comprised the majority (nearly half) of such cases. This observation suggests that RA may be responsible for the development of small airway disease along with smoking habit.

A reduced DLCO represents the earliest sign of the deterioration in pulmonary functions in patients with the pulmonary involvement of CTD. ${ }^{18}$ Accordingly, while most of other PFT parameters were normal, DLCO $\%$ was low among our study participants. Compatible with decreased PFTs, DLCO and 6MWT distance, two thirds of our study subjects had various levels of hypoxemia.

Pulmonary hypertension is a major cause of morbidity and mortality in pulmonary involvement of CTD. The highest incidence of PH (i.e. between 6 and 60\%) occurs in patients with PSS, ${ }^{20}$ while the reported figure for RA is approximately $21 \% .^{21}$ However, in contrast with previously reported data, the incidence of $\mathrm{PH}$ among patients with RA was higher than any other groups in our study. This finding may be related to the small sample size, or to a lower $\mathrm{PaO}_{2}$ level in RA patients in our study population. Thus, it may be reasonable to suggest that CTD patients including those with PSS also require a careful assessment with regard to the development of $\mathrm{PH} .{ }^{22}$
Our patients with $\mathrm{PH}$ had lower $\mathrm{FVC} \%$, FEV $1 \%$, DLCO\%, 6MWT, $\mathrm{PaO}_{2}$, and $\mathrm{SaO}_{2}$ as compared to those without $\mathrm{PH}$. Therefore, in patients with the pulmonary involvement of CTD, reduced PFT parameters, DLCO, $\mathrm{PaO}_{2}$, $\mathrm{SaO}_{2}$ and 6MWT distance should prompt an assessment of $\mathrm{PH}$.

Harrison et al. ${ }^{23}$ found pathological findings on HRCT of $44 \%$ of PSS patients despite normal chest X-ray findings. In our study, almost 20\% of patients with normal chest X-ray findings had pathological signs of pulmonary involvement on thorax HRCT. Therefore, chest X-rays may be inadequate to show pulmonary involvement in CTD patients and a HRCT imaging is recommended. Patients with honeycombing on thorax HRCT had significantly lower FVC\%, DLCO $\%, \mathrm{PaO}_{2}$, and $\mathrm{SaO}_{2}$ as compared to those without. These findings are consistent with the literature data suggesting that in contrast to ground-glass appearance on HRCT representing an early finding of pulmonary involvement of CTD, honeycombing is a late finding. ${ }^{24}$ In a study by Diot et al. ${ }^{25}$ comparing the respiratory function tests and HRCT findings in a group of patients with PSS, the reduced DLCO emerged as a sensitive indicator for the severity of pulmonary involvement, and a strong negative correlation between HRCT scores and DLCO was found. Our findings confirm that FVC\%, $\mathrm{FEV}_{1} \%, \mathrm{DLCO} \%, \mathrm{PaO}_{2}$, and $\mathrm{SaO}_{2}$ decrease more significantly in the presence of honeycombing on HRCT, as expected. There was also a significant association between SPAP and WHO and NYHA functional classes, and MRC and Borg dyspnea indices. This observation suggests that patients with higher dyspnea scores may require further assessments for the detection of pulmonary involvement.

A strong negative correlation between 6MWT distance and sPAP, Borg, MRC and WHO and NYHA functional classes was found among our study participants. On the other hand, the walking distance was positively correlated with FVC\%, $\mathrm{FEV}_{1} \%$, DLCO\%, $\mathrm{PaO}_{2}$ and $\mathrm{SaO}_{2}$. These observations suggest that 6MWT is a good indicator for the severity of pulmonary involvement in CTD.

In primary $\mathrm{PH}$, serum pro-BNP levels are elevated and correlate well with the functional 
class status. In patients with PSS, pro-BNP emerged as a biological marker for early $\mathrm{PH}$ in the absence of heart failure. ${ }^{26}$ Choi et al. ${ }^{27}$ observed a positive correlation between serum pro-BNP and age, blood pressure and SPAP and a negative correlation between pro-BNP and DLCO. As compared to interstitial lung disease, pro-BNP appeared to have a better predictive value for the presence of pulmonary vascular involvement in patients with PSS. To our best knowledge, no studies examining serum pro-BNP level in CTD other than PSS have been released in the literature. Therefore, our study is the first to analyze this relationship and to correlate it with other laboratory findings. Pro-BNP level was significantly elevated in subjects with $\mathrm{PH}$ when compared with the ones without. In all patients, serum pro-BNP correlated significantly negatively with DLCO\%, and significantly positively with sPAP. Also, as an additional piece of observation to the already existing data, pro-BNP levels correlated negatively with $\mathrm{FVC} \%, 6 \mathrm{MWT}, \mathrm{PO}_{2}$, and $\mathrm{SO}_{2}$ and positively with desaturation amount in 6MWT and BAL neutrophil percentage in our patient group. In the light of these data, it may be plausible to conclude that in all CTD patients with elevated serum pro-BNP, a worsening of functional parameters and a more severe $\mathrm{PH}$ are highly likely. We therefore hold the view that serum pro-BNP may provide important clues as to the severity of pulmonary involvement.

In a study by Strange et al., ${ }^{28}$ BAL neutrophil was found to be associated with worsening lung functions and pulmonary fibrosis. Witt et al. ${ }^{29}$ observed a more progressive course of the disease in predominantly granulocytic BAL microscopy, while those with normal or lymphocytic BAL results had stable lung functions for prolonged periods of time. BAL fluid examinations in patients with RA and SS previously showed a decline in the CD4+/CD8+ ratio. ${ }^{29,30}$ In agreement with literature data, most of our study subjects had decreased BAL CD4+/CD8+ ratio. Garcia et al. ${ }^{30}$ observed a negative correlation between the percent of neutrophils in BAL and DLCO. In another study examining patients with SS, BAL neutrophil count correlated with decreased DLCO and BAL neutrophil has been shown to play a significant role in the pathogenesis of pulmonary involvement in $\mathrm{SS} .{ }^{31} \mathrm{FVC} \%, \mathrm{FEV}_{1} \%, \mathrm{DLCO} \%$,
$\mathrm{PaO}_{2}, \mathrm{SaO}_{2}, 6 \mathrm{MWT}$, and sPAP were significantly lower in our patients with neutrophilic alveolitis as compared to other groups, while the New York Heart Association functional class was higher. A negative correlation between BAL neutrophil percentage and DLCO was also observed in our study, along with a significant negative correlation between $\mathrm{FVC} \%, \mathrm{PaO}_{2}$, $\mathrm{SaO}_{2}$, and 6MWT which was not reported previously. A significant positive correlation between pro-BNP, sPAP, $\mathrm{FEV}_{1} / \mathrm{FVC}$ ratio and desaturation amount was also detected. We concluded that BAL neutrophilia was associated with worsening of PFT parameters and increased frequency of $\mathrm{PH}$.

Patients with CTD, even when asymptomatic, should always be assessed with regard to possible pulmonary involvement, which is a major cause of morbidity and mortality. Besides chest X-ray, a HRCT examination, pulmonary functions and blood gases analyses, and 6MWT should be performed in all patients. $\mathrm{PH}$ is not only associated with PSS, but may also occur commonly in other CTDs. Serum pro-BNP levels may give diagnostic clues for the development of $\mathrm{PH}$ in CTD patients. Examination of BAL fluid is not only important for the differential diagnosis in CTD, but it also has prognostic implications because of the correlations with PFT and the existence of $\mathrm{PH}$. Functional parameters tend to worsen and $\mathrm{PH}$ may be more severe particularly in patients with neutrophilic alveolitis.

\section{Declaration of conflicting interests}

The authors declared no conflicts of interest with respect to the authorship and/or publication of this article.

\section{Funding}

The authors received no financial support for the research and/or authorship of this article.

\section{REFERENCES}

1. Lamblin C, Bergoin C, Saelens T, Wallaert B. Interstitial lung diseases in collagen vascular diseases. Eur Respir J Suppl 2001;32:69-80.

2. Du Bois RM, Wells AU. The lung and connective tissue diseases. In: Murray JF, Nadel JA, editors. Textbook 
of Respiratory Medicine. 3rd ed. Philadelphia: W.B Saunders; 2000. p. 1691-715

3. Crestani $\mathrm{B}$. The respiratory system in connective tissue disorders. Allergy 2005;60:715-34.

4. American Thoracic Society; European Respiratory Society. American Thoracic Society/European Respiratory Society International Multidisciplinary Consensus Classification of the Idiopathic Interstitial Pneumonias. This joint statement of the American Thoracic Society (ATS), and the European Respiratory Society (ERS) was adopted by the ATS board of directors, June 2001 and by the ERS Executive Committee, June 2001. Am J Respir Crit Care Med 2002;165:277-304.

5. Kim DS. Interstitial lung disease in rheumatoid arthritis: recent advances. Curr Opin Pulm Med 2006;12:346-53.

6. MacGregor AJ, Canavan R, Knight C, Denton CP, Davar J, Coghlan J, et al. Pulmonary hypertension in systemic sclerosis: risk factors for progression and consequences for survival. Rheumatology (Oxford) 2001;40:453-9.

7. Allanore Y, Borderie D, Avouac J, Zerkak D, Meune C, Hachulla E, et al. High N-terminal pro-brain natriuretic peptide levels and low diffusing capacity for carbon monoxide as independent predictors of the occurrence of precapillary pulmonary arterial hypertension in patients with systemic sclerosis. Arthritis Rheum 2008;58:284-91.

8. Arnett FC, Edworthy SM, Bloch DA, McShane DJ, Fries JF, Cooper NS, et al. The American Rheumatism Association 1987 revised criteria for the classification of rheumatoid arthritis. Arthritis Rheum 1988;31:315-24.

9. Tan EM, Cohen AS, Fries JF, Masi AT, McShane DJ, Rothfield NF, et al. The 1982 revised criteria for the classification of systemic lupus erythematosus. Arthritis Rheum 1982;25:1271-7.

10. Vitali C, Bombardieri S, Moutsopoulos HM, Balestrieri G, Bencivelli W, Bernstein RM, et al. Preliminary criteria for the classification of Sjögren's syndrome. Results of a prospective concerted action supported by the European Community. Arthritis Rheum 1993;36:340-7.

11. Preliminary criteria for the classification of systemic sclerosis (scleroderma). Subcommittee for scleroderma criteria of the American Rheumatism Association Diagnostic and Therapeutic Criteria Committee. Arthritis Rheum 1980;23:581-90.

12. Cotes JE, Dabbs JM, Elwood PC, Hall AM, McDonald A, Saunders MJ. Iron-deficiency anaemia: its effect on transfer factor for the lung (diffusiong capacity) and ventilation and cardiac frequency during sub-maximal exercise. Clin Sci 1972;42:325-35.

13. Mohamed Hoesein FA, Zanen P, Lammers JW. Lower limit of normal or FEV1/FVC $<0.70$ in diagnosing COPD: an evidence-based review. Respir Med 2011;105:907-15.
14. Burgel PR. The role of small airways in obstructive airway diseases. Eur Respir Rev 2011;20:23-33.

15. Fujimoto K, Matsuzawa Y, Yamaguchi S, Koizumi T, Kubo K. Benefits of oxygen on exercise performance and pulmonary hemodynamics in patients with COPD with mild hypoxemia. Chest 2002;122:457-63.

16. McLaughlin VV, Gaine SP, Howard LS, Leuchte $\mathrm{HH}$, Mathier MA, Mehta S, et al. Treatment goals of pulmonary hypertension. J Am Coll Cardiol. 2013;62(25 Suppl):D73-81.

17. Galiè N, Torbicki A, Barst R, Dartevelle P, Haworth $S$, Higenbottam T, et al. Guidelines on diagnosis and treatment of pulmonary arterial hypertension. The Task Force on Diagnosis and Treatment of Pulmonary Arterial Hypertension of the European Society of Cardiology. Eur Heart J 2004;25:2243-78.

18. Antoniou KM, Margaritopoulos G, Economidou F, Siafakas NM. Pivotal clinical dilemmas in collagen vascular diseases associated with interstitial lung involvement. Eur Respir J 2009;33:882-96.

19. Kostopoulos C, Rassidakis A, Sfikakis PP, Antoniades L, Mavrikakis M. Small airways dysfunction in systemic sclerosis. A controlled study. Chest 1992;102:875-81.

20. Chang B, Schachna L, White B, Wigley FM, Wise RA. Natural history of mild-moderate pulmonary hypertension and the risk factors for severe pulmonary hypertension in scleroderma. J Rheumatol 2006;33:269-74.

21. Dawson JK, Goodson NG, Graham DR, Lynch MP. Raised pulmonary artery pressures measured with Doppler echocardiography in rheumatoid arthritis patients. Rheumatology (Oxford) 2000;39:1320-5.

22. Demir N, Şahin A, Küçükşahin O, Kayacan O, Dinçer İ, Sayin T, et al. Pulmonary arterial hypertension and systemic sclerosis relation: a single centre experience. Heart Lung Circ 2014;23:667-73.

23. Goldin JG, Lynch DA, Strollo DC, Suh RD, Schraufnagel DE, Clements PJ, et al. High-resolution CT scan findings in patients with symptomatic scleroderma-related interstitial lung disease. Chest 2008;134:358-67.

24. Racz H, Mehta S. Dyspnea due to pulmonary hypertension and interstitial lung disease in scleroderma: room for improvement in diagnosis and management. J Rheumatol 2006;33:1723-5.

25. Diot E, Boissinot E, Asquier E, Guilmot JL, Lemarié $\mathrm{E}$, Valat $\mathrm{C}$, et al. Relationship between abnormalities on high-resolution CT and pulmonary function in systemic sclerosis. Chest 1998;114:1623-9.

26. Dimitroulas T, Giannakoulas G, Karvounis H, Sfetsios T, Koliakos G, Parcharidis G, et al. Neurohormonal activation in patients with systemic sclerosis-related pulmonary arterial hypertension. Int $\mathrm{J}$ Cardiol 2007;121:135-7.

27. Choi HJ, Shin YK, Lee HJ, Kee JY, Shin DW, Lee $\mathrm{EY}$, et al. The clinical significance of serum $\mathrm{N}$-terminal pro-brain natriuretic peptide in systemic sclerosis patients. Clin Rheumatol 2008;27:437-42. 
28. Strange Bolster MB, Roth MD, Silver RM, Theodore A, Goldin J, Clements P, et al. Bronchoalveolar lavage and response to cyclophosphamide in scleroderma interstitial lung disease. Am J Respir Crit Care Med 2008; 177:91-8.

29. Witt C, Borges AC, John M, Fietze I, Baumann G, Krause A. Pulmonary involvement in diffuse cutaneous systemic sclerosis: broncheoalveolar fluid granulocytosis predicts progression of fibrosing alveolitis. Ann Rheum Dis 1999;58:635-40.
30. Garcia JG, Parhami N, Killam D, Garcia PL, Keogh BA. Bronchoalveolar lavage fluid evaluation in rheumatoid arthritis. Am Rev Respir Dis 1986;133:450-4.

31. Salaffi F, Manganelli P, Carotti M, Baldelli S, Blasetti $\mathrm{P}$, Subiaco S, et al. A longitudinal study of pulmonary involvement in primary Sjögren's syndrome: relationship between alveolitis and subsequent lung changes on high-resolution computed tomography. Br J Rheumatol 1998;37:263-9. 